\title{
pH electrodes based on iridium oxide films for marine monitoring
}

\author{
Zhengwen Zhou ${ }^{\mathrm{a}, \mathrm{b}, 1}$, Juan $\mathrm{Li}^{\mathrm{c}, 1}$, Dawei Pan ${ }^{\mathrm{a}, \mathrm{b}, \mathrm{d}, *}$, Hong Wei ${ }^{\mathrm{a}, \mathrm{b}}$, Chenchen Wang ${ }^{\mathrm{a}, \mathrm{b}}$, \\ Fei Pan ${ }^{\mathrm{a}, \mathrm{b}}$, Jianjun Xia ${ }^{\mathrm{c}, * *}, \mathrm{Su} \mathrm{Ma}^{\mathrm{a}, \mathrm{e}}$ \\ a Key Laboratory of Coastal Environmental Processes and Ecological Remediation, Yantai Institute of Coastal Zone Research, Chinese Academy of Sciences, \\ Yantai, 264003, PR China \\ ${ }^{\mathrm{b}}$ University of Chinese Academy of Sciences, Beijing, 100049, PR China \\ ${ }^{\mathrm{c}}$ Research and Development of Center, China Tobacco Yunnan Industrial Co., Ltd., Kunming, 650231, PR China \\ 'Center for Ocean Mega-Science, Chinese Academy of Sciences, 7 Nanhai Road, Qingdao, 266071, PR China \\ e College of Chemistry, Chemical Engineering and Materials Science, Shandong Normal University, Jinan, 250014, PR China
}

\section{A R T I C L E I N F O}

\section{Article history:}

Received 11 December 2019

Received in revised form 24 January 2020

Accepted 24 January 2020

\section{Keywords:}

$\mathrm{pH}$ electrodes

$\mathrm{pH}$ value detection

Marine environmental monitoring

Iridium oxide films

Electroanalysis

\begin{abstract}
A B S T R A C T
The $\mathrm{pH}$ is an important parameter that affects the growth and development of marine organisms, environmental changes, and industrial and agricultural production processes. Nowadays, important trends in $\mathrm{pH}$ detection and analysis are higher stability, adaptation to extreme environmental conditions, miniaturization, portability, and digital intelligence. Several studies have focused on the application of the iridium oxide film (IROF) pH electrodes in water quality monitoring and physiological analysis. The central aim of this work was to review the preparation techniques of the IROF pH electrodes and to expand their application in the field of marine monitoring. The studied methods include electrochemical deposition, electrochemical growth, sputtering deposition, heat treatment, and novel preparation methods. The IROF $\mathrm{pH}$ electrodes prepared via these methods are more sensitive, have a wider $\mathrm{pH}$ measurement ranges, and can be miniaturized further than traditional glass and pH photometer. Hence, in environmental analysis, combining IROF pH electrodes with wireless technology for the physiological and biochemical analysis of marine organisms, seawater, and sediment pore water is an important development tendency.
\end{abstract}

(C) 2020 Elsevier B.V. All rights reserved.

\section{Introduction}

The $\mathrm{pH}$ is an essential parameter in ecological environments and biological organisms, and different $\mathrm{pH}$ values can influence the growth rate of cells, metabolic rates, cell division, and differentiation [1-4]. Some researchers have shown that the carbon cycles of marine coral ecosystems and even of global ecosystems are affected by fluctuating $\mathrm{pH}$ values, and $\mathrm{pH}$ fluctuations caused by wastewater discharge into upstream rivers will also affect downstream ecosystems [5-8]. Therefore, stable and continuous $\mathrm{pH}$ monitoring is essential in agroecology, environmental monitoring/detection, industrial production, and other fields.

In particular, due to the continuous increase in global carbon dioxide emissions, a large amount of $\mathrm{CO}_{2}$ is absorbed by the ocean,

\footnotetext{
* Corresponding author at: Key Laboratory of Coastal Environmental Processes and Ecological Remediation, Yantai Institute of Coastal Zone Research, Chinese Academy of Sciences, Yantai, 264003, PR China.

** Corresponding author.

E-mail addresses: dwpan@yic.ac.cn (D. Pan), lordxia@126.com (J. Xia).

1 These authors contributed equally to this work.
}

making ocean acidification a global environmental problem. Based on previous studies, ocean acidification will further release heavy metals deposited in the ocean sediment, reduce the calcification degree of shellfish, and dissolve the foundation of coral reefs [3,5]. The exact impacts of ocean acidification on the marine biological chain are currently not clear, requiring the use of instruments that can stably monitor the $\mathrm{pH}$ of the ocean.

Traditional $\mathrm{pH}$ glass membrane electrodes can maintain stable and accurate $\mathrm{pH}$ measurements in commonly used $\mathrm{pH}$ ranges and are still widely used. However, these electrodes have some limitations, such as large probe volumes, difficulties in miniaturization, easily damaged hydrated glass films, and high impedance and long response times under alkaline conditions [9-11]. Over the past decades, scholars have found that metal oxides such as $\mathrm{PtO}_{2}$, $\mathrm{IrO}_{2}, \mathrm{RuO}_{2}, \mathrm{OsO}_{2}, \mathrm{Ta}_{2} \mathrm{O}_{5}, \mathrm{Ti}_{2} \mathrm{O}, \mathrm{PdO}$, and $\mathrm{SnO}_{2}$ can be used to prepare $\mathrm{pH}$ sensors [12-14]. Compared with traditional pH glass membrane electrodes, these metal oxide $\mathrm{pH}$ electrodes exhibit superNernst phenomena and have simple and cheaper fabrication processes [15]. Moreover, using these metal oxides as pH sensing materials makes it easier to miniaturize a variety of sensor shapes [16]. Among these metal oxide electrode materials, iridium and its oxides have attracted the most attention. Electrodes based on 


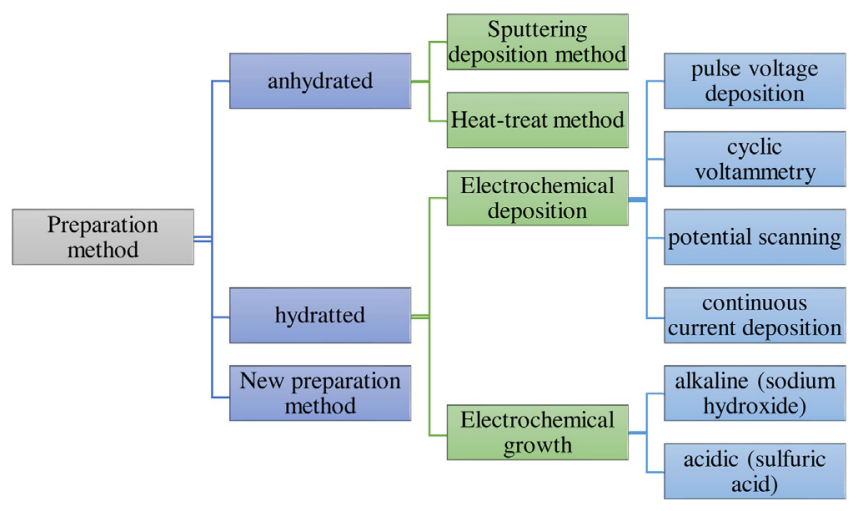

Fig. 1. Classification and summary of preparation methods of IROF-based electrodes.

iridium and its metal oxides are relatively stable and insoluble in measured solutions, but also have short response times, wide measurement ranges, high temperature (up to $250^{\circ} \mathrm{C}$ ) and pressure limitations, and tolerance to corrosive environments $[10,17,18]$. Hence, some researchers combined these advantages of IROFs to further develop the application of iridium and its metal oxide film $\mathrm{pH}$ electrode in specific fields. This paper will focus on the summarization of its preparation methods, research in the field of marine analysis and monitoring, and its potential application in the future.

\section{Preparation of iridium oxide films electrodes}

Iridium oxide films have been used in a variety of electrochromic materials, electrocatalysts, nerve stimulants, supercapacitors, and pH-sensing materials $[19,20]$. When used for $\mathrm{pH}$ sensing, these materials are mainly divided into hydrated and unhydrated membranes. The thickness and particle size of IROFs fabricated by different methods are diverse. Usually, $\mathrm{pH}$ electrodes prepared using electrochemical growth and electrochemical deposition are hydrated IROF electrodes. The preparation methods of the anhydrous films mainly include heat-treatment and heatsputtering processes [19,21-24]; these methods are described in detail in Fig. 1.

\subsection{Electrochemical deposition}

Electrodeposition is used to deposit IROFs on various substrates, which are generally conductive materials such as lead, platinum, stainless steel, and graphite. Some non-conductive substrates, such as glass and plastics, have also been used $[25,26]$. Electrochemical deposition uses a complex deposition solution, and the role of each component should be considered to ensure uniformity and stability of the coating [27]. In previous works, standard electrodeposition solutions have contained $\mathrm{IrCl}_{4}$, iridium
(IV) oxalate, and some other weak salt ligand ions. During electrodeposition, it is necessary to adjust the $\mathrm{pH}$ value of the electrodeposition solution, control the potential sweep range during deposition, and select the appropriate deposition time $[13,28,29]$. Common electrochemical deposition methods are listed in Table 1, which mainly include continuous current deposition [30,31], pulse voltage deposition [32], potential scanning, and cyclic voltammetry (CV) $[33,34]$.

The requirements of the deposition solution for IROFs deposited by the above methods are different, and therefore, the allocation of deposition solution components has become critical for electrochemical deposition [22,41]. Zea et al. attempted to directly print a novel platinum nanoparticle ink to promote the adhesion of a deposited sensing material [36]. Then, a solid-state $\mathrm{pH}$ electrode was functionalized with anodic electrodeposited iridium oxide films on a rough nanostructured platinum-printed layer. Because it is compatible with any electrode design in the micrometer range, the design shown in Fig. 2A provides a novel intelligent wearable monitoring technology. Fig. 2B demonstrates a new IROF pH sensor based on a flexible polyimide substrate fabricated by Huang et al. The main procedure included the deposition of a 7-nm thick layer of $\mathrm{Cr}$ on a polyimide substrate, followed by a $0.1-\mu \mathrm{m}$ thick layer of Au. Subsequently, the electrodes were exposed to an SU-8 sacrificial layer, and the IROF was formed by a sol-gel process [22,42]. Fig. 2C shows the IROF pH electrode at the micron level. Such IROF pH electrodes on flexible substrates are suitable for practical applications on curved surfaces and will enable numerous new applications.

\subsection{Electrochemical growth}

Previously, some scholars have applied a layer of iridium salt, followed by cyclic voltammetry deposition, in a method called cyclic voltammetric growth. A distinction can be made between these methods by noting that any deposition or current circulation after applying a coating applied is called an electrodeposition method. One in which the iridium wire is not coated and is directly embedded in the electrochemical cycle is an electrochemical growth method.

The IROF electrodes made by electrochemical cyclic voltammetry are commonly formed in acidic (sulfuric acid) or alkaline (sodium hydroxide) electrolyte solutions [43,44]. When pure iridium wire is electrochemically activated in an electrolyte solution, the hydrated IROFs will grow on the surface of the iridium wire [45]. Cyclic voltammetry is a simple method for preparing IROFs because it is fast and only the cyclic potential needs to be controlled and the number of cyclic scans needs to be optimized. However, the electrodes created by cyclic voltammetry have poor reproducibility and potential drift. The IROF-based $\mathrm{pH}$ electrodes prepared by cyclic voltammetry usually exhibit superNernst phenomenon, and electrode sensitivity ranges from -60 to $-80 \mathrm{mV} / \mathrm{pH}$ unit $[24,43,46]$.

Table 1

Common techniques and methods for electrochemical deposition, deposition substrates, deposition solutions, and pH response ranges.

\begin{tabular}{|c|c|c|c|c|c|}
\hline Substrates & Deposition methods & Deposition solution & Range of pH response & $\begin{array}{l}\text { Sensitivity curve } \\
\text { slope }(\mathrm{mV} / \mathrm{pH})\end{array}$ & References \\
\hline $\mathrm{Pt}$ & $\mathrm{CV}$ & $\mathrm{IrCl}_{4} \cdot \mathrm{xH}_{2} \mathrm{O}, \mathrm{C}_{2} \mathrm{H}_{2} \mathrm{O}_{4}, \mathrm{H}_{2} \mathrm{O}_{2}$ mixed solution & $1-13$ & $-60.5 \pm 5$ & [35] \\
\hline Pt ink & Dynamic potential scanning & $\mathrm{IrCl}_{3} \cdot 3 \mathrm{H}_{2} \mathrm{O}, \mathrm{C}_{2} \mathrm{H}_{2} \mathrm{O}_{4} \cdot \mathrm{H}_{2} \mathrm{O}, \mathrm{K}_{2} \mathrm{CO}_{3}$ mixed solution & $2-11$ & $-71.3 \pm 0.3$ & [36] \\
\hline Glassy carbon electrode & $\mathrm{CV}$ & $\mathrm{Na}_{2} \mathrm{IrCl}_{6}, \mathrm{PdCl}_{2}$ mixed solution & $1-5$ and $6-10$ & -62.0 and -83.0 & [37] \\
\hline $\begin{array}{l}\text { Ti, Au nanoparticle } \\
\text { coated a glass }\end{array}$ & $\mathrm{CV}$ & $\mathrm{IrCl}_{4}, \mathrm{H}_{2} \mathrm{O}_{2}, \mathrm{C}_{2} \mathrm{H}_{2} \mathrm{O}_{4} \cdot \mathrm{H}_{2} \mathrm{O}, \mathrm{K}_{2} \mathrm{CO}_{3}$ mixed solution & $4-10$ & -70.5 & [38] \\
\hline Ti ring & $\mathrm{CV}$ & ditto & $8-12$ & -75.0 to -83.0 & [39] \\
\hline Au disc & Constant potential & ditto & $2-11$ & -74.3 & {$[40]$} \\
\hline$\left(\mathrm{SnO}_{2}: \mathrm{F}\right)$ glasses & anodic current density & $\mathrm{K}_{3} \mathrm{IrC}_{6}, \mathrm{~K}_{2} \mathrm{CO}_{3}, \mathrm{C}_{2} \mathrm{H}_{2} \mathrm{O}_{4} \cdot 2 \mathrm{H}_{2} \mathrm{O}$ mixed solution & Not given & Not given & [23] \\
\hline tin-doped- $\operatorname{In}_{2} \mathrm{O}_{3}$ & constant current density & {$\left[\mathrm{Ir}(\mathrm{OH})_{6}\right]^{2-}, \mathrm{NaOH}, \mathrm{NaCl}$ mixed solution } & $2-12$ & Not given & {$[21]$} \\
\hline
\end{tabular}




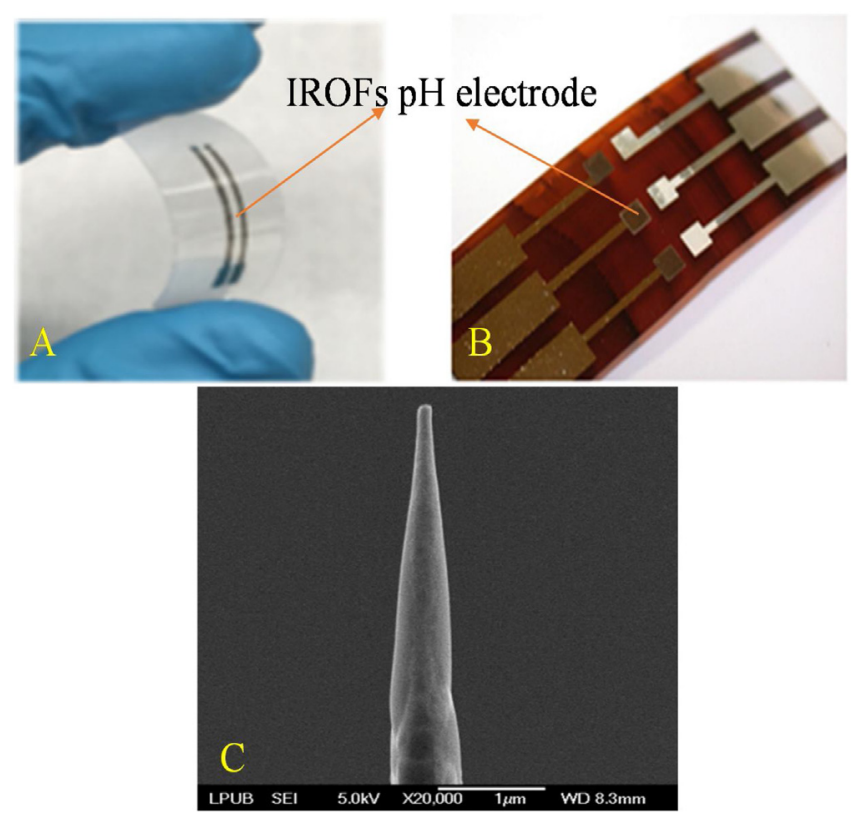

Fig. 2. Electrodeposited matrix materials with different shapes [(A) Reprinted with permission from Zea et al. (2019) Copyright (C) American Chemical Society; (B) Reprinted with permission from Huang et al. (2011) Copyright (C) Elsevier; (C) Reprinted with permission from Ndobo-Epoy et al. (2007) Copyright (C) American Chemical Society].

\subsection{Sputtering deposition methods}

Sputtering deposition, sputtering iridium salt on a substrate in oxygen or nitrogen atmosphere, called sputtering iridium oxide films (SIROFs), is also a popular method for preparing IROFs. Single crystal silicon, $\mathrm{Al}_{2} \mathrm{O}_{3}$, stainless steel, and other metallic materials are commonly used as substrates for sputtering $[47,48]$. The sensitivity E-pH of an electrode films manufactured by a sputtering method is generally similar to the Nernst standard value and has high repeatability. Compared with electrodes prepared by cyclic voltammetry, the stability of the electrodes potential and the interference characteristics of antioxidant reduction ions are often affected by other physical parameters (e.g., $\mathrm{O}_{2}$, Ar partial pressure, temperature, humidity, deposition rate, substrate temperature, electric field, etc.) $[48,49]$. The sputtering deposition method requires relatively harsh experimental conditions and expensive equipment, leading to fewer reports using this method.

\subsection{Heat-treatment methods}

Compared with the other methods, a remarkable advantage of the thermal oxidation method is that IROF electrodes fabricated in this manner have long-term stability and less potential drift [50]. The thermal oxidation method requires matrix materials capable of tolerating high temperatures, since this technique requires temperatures of $300-400{ }^{\circ} \mathrm{C}$, with some requiring temperatures higher than $800^{\circ} \mathrm{C}[50,51]$. The thermal oxidation method mainly involves $\mathrm{IrCl}_{3}$ thermal decomposition, molten salt oxidation, and direct ignition of a mixture containing iridium or a sol-gel which is coated on a thermostable substrate. Then, the IROFs are formed by high-temperature oxidation [52,53]. The molten salt oxidation method involves coating nitrate or carbonate on a high-temperature resistant matrix, followed by quenching the oxide solution one or more times to form an IROF on the surface [54].

The direct burning method involves soaking iridium wire in a stable alkali solution, which quenches and oxidizes the iridium surface at high temperatures to produce the IROFs. The main distinction between this method and cyclic voltammetry under alkaline conditions is the oxidation mode. Since thermal oxidation requires high temperatures, polymeric materials and photoimpedance materials cannot be used as sacrificial oxide layers when coating a solution on the electrode matrix. At the same time, the length and frequency of burning, the oxidation temperature, and the cooling method can affect the thickness of the film and the morphology of surface particles. Furthermore, oxidation temperature and thermal oxidation time also affect the $\mathrm{pH}$ response time [55]. Since most IROFs obtained by thermal oxidation are anhydrous, it is necessary to complete the hydration reaction on the surface before determining the $\mathrm{pH}$ of the solution. Therefore, a slightly longer response time may be required. Although the electrodes prepared by thermal oxidation have excellent stabilities, cracks in the oxide film on the surface naturally occur due to the high temperatures, which reduces the service life of the electrodes [22]. Thermal oxidation and sputtering methods require high-temperature oxidation, but these also require more complex and expensive systems, significantly limiting the applications of these methods.

\subsection{New preparation method}

Apart from the traditional preparation methods of IROFs $\mathrm{pH}$ electrodes using iridium wires or other substrates, there are also relatively novel methods where nano iridium oxide is directly pressed and oxidized in an oxygen atmosphere. This method uses prepared nano iridium oxide doped with a polymethyl methacrylate (PMMA) matrix as an active sensing material for conductors and hydrogen ions. Nano iridium oxide particles are dispersed in a PMMA suspension, rapidly precipitated in water, and subsequently, the nano iridium oxide composite electrode is formed using compression molding [1]. Direct oxidation under an oxygen atmosphere oxidizes very few areas on the surface of the electrode, while the use of large-scale oxidation results in uneven and incomplete surface oxidation. Ndobo-Epoy et al. [56] covered an iridium filament surface with a poly- $p$-xylene insulating layer, while Ga used a focused ion beam to open an iridium filament vertex which was then oxidized in an oxygen atmosphere for $12 \mathrm{~h}$ to prepare a nanoscale IROF pH electrode.

\section{Application of iridium oxide film pH electrodes}

In the above, several methods of making IROFs are introduced. Each of these methods has its own advantages and disadvantages. The specific situation depends on the existing conditions and study requirements. The most important aspect is to introduce the differences between these new IROF pH electrodes and electrodes generated by traditional methods and the trend of innovative application in marine environment analysis. The relationship between IROF electrodes and its application in marine monitoring is shown in Fig. 3.

\subsection{Marine organisms}

Based on the miniaturization of IROF $\mathrm{pH}$ electrodes, $\mathrm{pH}$ values can be measured at specific sites for cell and physiological reactions to further understand the surface proton transfer of some crustaceous marine organisms in acidified oceans. Sensors used to measure biochemical pH values in cells should use selected appropriate matrix materials for the objects they detect and monitor. They also need to be miniaturized, typically trending to the $\mu \mathrm{m}$-pm level, to avoid effects on the growth and biochemical reactions of biological cells. Carbon fibers are the most common matrix materials in biochemistry and physiology and simultaneously meet such high requirements. There have been several 


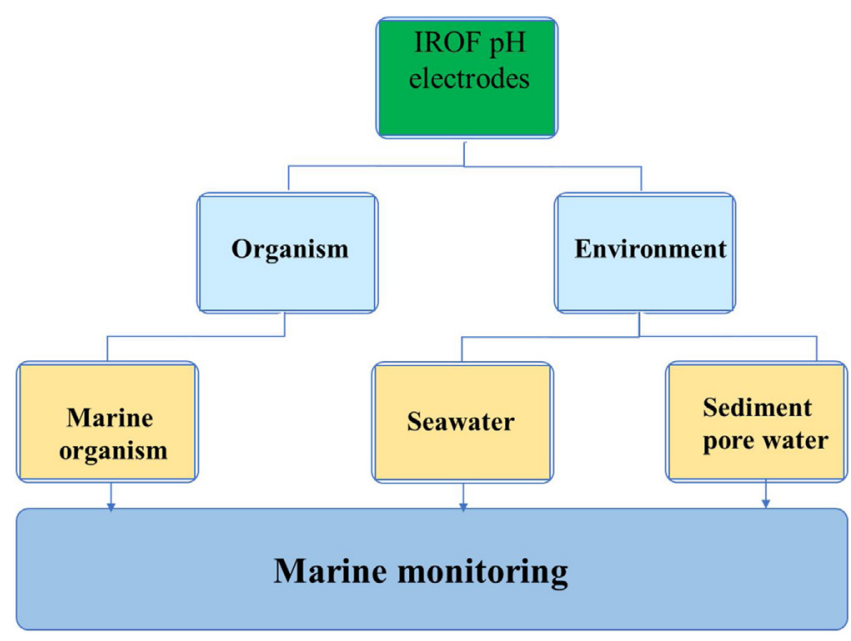

Fig. 3. Application of iridium oxide films $\mathrm{pH}$ sensors in marine monitoring.

excellent reviews and books summarizing the direction and application for biochemical and physiological analyses [56-58]. For example, Cork et al. inserted iridium oxide microelectrodes into the subdiaphragmatic vagus nerve of anesthetized rats, and the microelectrodes were sufficiently pH-sensitive to quickly detect changes in $\mathrm{pH}$ values associated with the intestinal hormone cholecystokinin (CCK) and gastric distention [59]. This work demonstrated the vital role of $\mathrm{pH}$ in the growth and reproduction of organisms. At the same time, the IROF $\mathrm{pH}$ electrode provides a new support for exploring the physiological $\mathrm{pH}$ fluctuation of marine organisms. Generally, the primary purpose of a $\mathrm{pH}$ sensor is to determine the $\mathrm{pH}$ of marine environments to explain and evaluate how the $\mathrm{pH}$ affects the survival of organisms. Based on previous studies, $\mathrm{pH}$ fluctuations caused by ocean acidification adversely affect the survival of calcified polychaete species [60], mussel larvae [61], and bivalves [62]. For example, Lane et al. revealed that when the $\mathrm{pH}$ of the metamorphic larvae of myxophora decreased, the ability of the larvae to calcify the pipeline was reduced or even lost entirely [63]. Previously, Wipf et al. prepared a pH microelectrode by depositing aqueous oxidized iridium onto a carbon fiber microelectrode which showed two linear regions of potential response between pH 2-6 and pH 6-12. The prepared electrode could monitor the proton reaction of the interface by applying a scanning electron microscope as a probe to obtain the dynamic $\mathrm{pH}$ change at the surface [64]. Iridium oxide microelectrodes have sufficient $\mathrm{pH}$ sensitivity to readily detect $\mathrm{pH}$ changes in their environments. Zhao et al. synthesized $\mathrm{N}$-(6-aminopyridin-2-yl) ferrocene to develop a two-channel electrochemical ratiometric biosensor for local $\mathrm{pH}$ determination in a live rat brain, which will potentially provide a new research perspective and application scope for the IROF pH electrode [65]. Thus, we believe that the miniaturization of IROF pH electrodes can further reveal the proton transfer in somatic cells of the metamorphic larvae of myxoplasma spp. during pipeline calcification.
In addition, IROF pH electrodes can also be used to determine the $\mathrm{pH}$ of biological samples and tissue culture media and for realtime monitoring of $\mathrm{pH}$ changes in culture media to more objectively and accurately assess the biological condition of cultures [66,67]. Tabata et al. successfully monitored proton release during an amplification reaction in real-time, using a miniature $\mathrm{pH}$ electrode, and demonstrated the quantitative detection of nucleic acids [68]. Vanhoudt et al. reduced a $\mu \mathrm{m}$ scale to the pm-scale by anodic polarization and protected the iridium $\mathrm{pH}$ electrode by cyclic voltammetry in $0.5 \mathrm{M}$ sulfuric acid by placing silk in a capillary glass tube [41]. Similarly, IROF $\mathrm{pH}$ electrodes can also be employed to measure $\mathrm{pH}$ values in biological samples and tissue culture media. During ocean acidification simulations, the acidification rate of some biological cells and other indicators should be measured. In the meantime, Ges et al. generated microfluidic chips $(20 \mu \mathrm{m} \times 400 \mu \mathrm{m})$ with two IROF electrodes; the acidification rate of cultured cells was obtained by a reproducible voltage difference between two IROF electrodes [69]. These multidimensional analytical methods of marine organisms using IROF pH electrodes can be used to explore the mechanism of these $\mathrm{pH}$ stresses to develop more targeted protective measures. There is no doubt that $\mathrm{pH}$ may not be the only factor affecting biological growth, but it is necessary to monitor the parameters of these potential effects through adequately designed experiments. In the future, more and more researchers will pay attention to the properties of IROFs as a pH-sensitive material when the traditional $\mathrm{pH}$ glass electrode cannot be used.

\subsection{Seawater}

The $\mathrm{pH}$ value is an index that must be measured during the monitoring of ecological environments and water quality because it directly determines the state of some environmental pollutants or sediments in water. A comparison of commonly used instruments for $\mathrm{pH}$ monitoring of marine water quality is shown in Table 2. The IROF pH electrode is not affected by turbidity and can be applied for $\mathrm{pH}$ monitoring in estuarine areas with high turbidity. Based on the advantages of IROF pH electrodes, it is reasonable to apply them in marine water quality monitoring. Nadappuram et al. fabricated nanoscale dual-function pH scanning ionic conductivity microscopy (SICM) probes using carbon electrodes coated with iridium oxide. By measuring the distance of the tip of the electrode, a high-resolution three-dimensional $\mathrm{pH}$ diagram was generated [70]. Salimi et al. did not confine their study to simply determining the $\mathrm{pH}$ value by the IROF electrode. Borondoped diamond (BDD) electrodes, obtained by electrochemical deposition, were used to modify IROFs for the detection of ultratrace amounts of environmental arsenic and mercury, which greatly broadened the applications of the IROFs electrode [71,72]. Zhang et al. applied the IROF pH electrodes prepared by an electrogrowth method to determine the $\mathrm{pH}$ value of a marine environment, and the results were more stable than those obtained by a traditional glass electrode [73]. Using the characteristics of IROF $\mathrm{pH}$ electrodes to fabricate a multi-parameter integrated environmental monitoring sensor is also an important future direction for

Table 2

Comparison of commonly used instruments for $\mathrm{pH}$ monitoring of marine water quality.

\begin{tabular}{|c|c|c|c|c|c|}
\hline Instrument & Accuracy $(\mathrm{pH})$ & pH Range & Weight (Kg) & Temperature Range $\left({ }^{\circ} \mathrm{C}\right)$ & Applicable scenario \\
\hline Deep SeapHOx ${ }^{\mathrm{TM}}$ V2 & \pm 0.05 & $6.5-9.0$ & 5.4 & $-5-45$ & $\begin{array}{l}\text { Nearshore ocean and deep sea within } \\
2000 \mathrm{~m}\end{array}$ \\
\hline PHBJ-260F glass pH electrode & $\pm 0.01 \sim 0.10$ & $-2.0-20.0$ & 0.3 & $-5-105$ & Shallow low-turbidity water \\
\hline IROFs pH electrode & $\pm 0.01 \sim 0.10$ & $2.0-12.0$ & about 0.1 & $10-200$ & $\begin{array}{l}\text { Nearshore estuary with high turbidity } \\
\text { or open sea area within } 100 \mathrm{~m}\end{array}$ \\
\hline spectrophotometric pH sensor & \pm 0.008 & $7.6-8.2$ & 3.0 & $15-30$ & $\begin{array}{l}\text { Aquaculture, offshore low-turbidity } \\
\text { surface water area }\end{array}$ \\
\hline
\end{tabular}




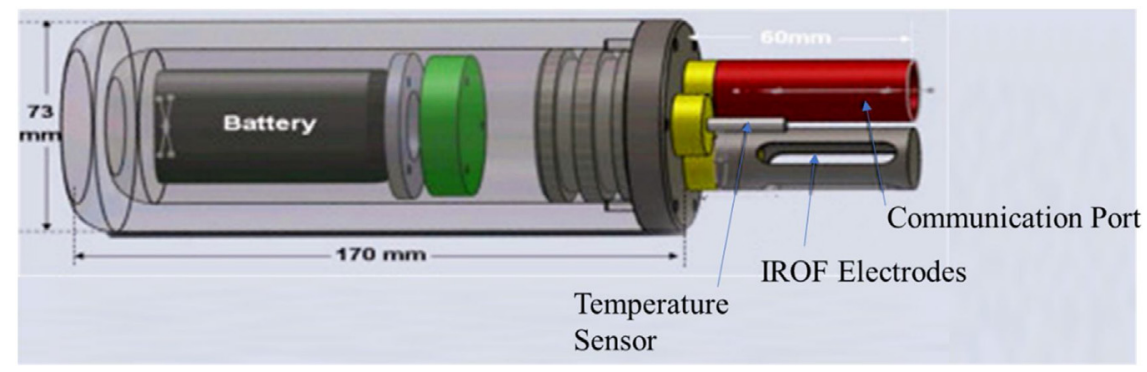

Fig. 4. Scheme showing the IROF pH electrode for seawater pH monitoring [Reprinted with permission from Ding et al. (2011) Copyright @ Elsevier].

environmental monitoring [74]. A multi-parameter real-time continuous water quality monitoring system has been reported by Defe et al., which can further reduce the cost and maintain highprecision measurements [75]. Wu et al. simultaneously measured the $\mathrm{pH}$ value, oxidation potential $E_{\mathrm{h}}$, and $\mathrm{H}_{2} \mathrm{~S}$ concentration in a deep-sea environment using a self-made multi-parameter integrated sensor [76]; the schematic figure of the $\mathrm{pH}$ electrode is shown in Fig. 4. The two most important parts, the data exchange port and the integrated electrode, are presented.

Marine environmental quality data is heading towards intelligent terminals and wireless transmission. The application of IROF $\mathrm{pH}$ electrodes in marine environmental monitoring includes their applications in ocean buoys, which are integral parts of marine environmental water quality detection. The convenient detection of $\mathrm{pH}$ can be obtained through self-designed electrode shapes or assembly in electronic equipment modules, connected to a signal digital conversion system (DCS), data transmission of IROF electrode potential data, and signal processing with intelligent terminals [36]. Currently, remote data transmission is being implemented in some offshore areas, but terminal monitoring sensors are expensive. Combining IROF pH electrodes with ocean buoys can effectively reduce costs and achieve long-term monitoring of more extensive areas in seas and rivers. With the development of informationization, integrated intelligent monitoring systems based on $\mathrm{pH}$ and other parameters have also been developed. Ding and Ma constructed a wireless sensor network system using embedded computing, micro-electromechanical systems (MEMS), distributed information processing, and wireless communication. The system could digitize, network, and could monitor seawater quality in real-time [77]. It is also an important trend for environmental analysis to connect monitoring and analysis equipment with smart phone terminals and read data through common smart phones. Sun et al. developed a $\mathrm{pH}$ indicator system based on a smartphone platform, which connected to a self-made $\mathrm{pH}$ sensor through a headphone interface. After connection, it could be used to test and analyze sputum samples from cystic fibrosis (CF) patients [78]. By applying these technologies, real-time data transmission can be displayed on intelligent terminals, which increases the convenience of $\mathrm{pH}$ monitoring in these fields.

\subsection{Sediment pore water}

The $\mathrm{pH}$ value of sediment and its pore water will affect the growth and development of benthic organisms and the distribution of sediment bacteria. Current methods for determining the $\mathrm{pH}$ of pore water in sediments mainly include the application of glass electrodes and Raman spectrometry [79]. The application of $\mathrm{pH}$ glass electrodes requires a higher pore water content in sediments, and the measurement of multiple samples at intervals requires complex cleaning. Traditional $\mathrm{pH}$ microelectrodes consist of a glass film, and an $\mathrm{Ag} / \mathrm{AgCl}$ electrode, and a saturated calomel electrode is combined to form a measurement system. Archer et al. used a polymethyl methacrylate (PMMA) glass microelectrode to measure the $\mathrm{pH}$ profile of deep-sea sediments to obtain the dissolution rates of seabed sediments [80]. However, the $\mathrm{pH}$ glass film was damaged during tests, and the microelectrode was therefore not suitable for in situ measurements. The principle of determining the $\mathrm{pH}$ of pore water in sediments using Raman spectroscopy is based on the conjugated acid-base pair of $\mathrm{H}_{2} \mathrm{~S}$ and $\mathrm{HS}^{-}$, whose concentration ratio is a function of $\mathrm{pH}$. The Raman spectra of sulfide-containing solutions with different $\mathrm{pH}$ values showed regular changes in the characteristic Raman overlap peaks and $\mathrm{H}_{2} \mathrm{~S}$. There is a particular coupling relationship between Raman spectroscopic parameters of sulfides and solution $\mathrm{pH}$ for the HS $^{-}$peak [81]. The main disadvantage of using Raman spectroscopy to determine $\mathrm{pH}$ is that the measurement range is too narrow, with values between 6.11 and 8.32 [82]. Materials based on IROF $\mathrm{pH}$ electrodes have more comprehensive measurement ranges and can directly measure the specific thickness of sediment in situ. Pore water data of different sediment layers, which are closer to the sample parameters, can be obtained. Xu et al. prepared iridium and tungsten oxide $\mathrm{pH}$ microelectrodes to measure the vertical profiles of sediment pH in the Xiamen West Sea and Jiulong River Estuary [83]. The $\mathrm{pH}$ reached a minimum at the interface of aerobic and anaerobic depths $(4-5 \mathrm{~mm})$ and tended to remain stable at $20 \mathrm{~mm}$. In addition, the effect of $S^{2-}$ on the microelectrode sensor was eliminated by Nafion reagent leaching.

\section{Conclusions and future perspectives}

In light of the importance of $\mathrm{pH}$ measurements, the use of iridium oxide films as $\mathrm{pH}$-sensing material has emerged as a popular research topic. Numerous studies have shown that the IROF $\mathrm{pH}$ electrode can determine the required $\mathrm{pH}$ parameters easily and in-situ real-time, and future analysis and determination will not be limited to the laboratory, in contrast to the use of traditional $\mathrm{pH}$ glass electrodes. In this paper, we introduce the role of IROF $\mathrm{pH}$ electrodes in water analysis and expand their application in the comprehensive analysis of marine environments, including marine organisms and sediment pore water.

Nowadays, it is an important trend in environmental analysis to measure environmental parameters in a diversified, digital, and intelligent way. The solid-state IROF pH electrode is combined with remote wireless technology to realize the multi-parameter recording of the open sea. With electrode miniaturization, the impact of $\mathrm{pH}$ on marine organisms and the impact of ocean acidification on the environment and organisms can be further analyzed and evaluated.

\section{Declaration of Competing Interest}

The authors declare that they have no known competing financial interests or personal relationships that could have appeared to influence the work reported in this paper. 


\section{Acknowledgements}

This work was financially supported by the STS Project of the Chinese Academy of Sciences (KFJ-STS-ZDTP-023), the Key Research and Development Plan of Shandong Province (2017GHY215002), the Senior User Project of RV KEXUE (KEXUE2018G04), and the Key Research and Development Plan of Yantai City (2017ZH096).

\section{Appendix A. Supplementary data}

Supplementary material related to this article can be found, in the online version, at doi:https://doi.org/10.1016/j.teac.2020. e00083.

\section{References}

[1] J. Park, M. Kim, S. Kim, Surface renewable nano-iridium oxide polymeric composite pH electrodes, Sens. Actuators B 204 (2014) 197-202. http:// 10.1016/j.snb.2014.07.104.

[2] C.J. Kennedy, C. Picard, Chronic low pH exposure affects the seawater readiness of juvenile Pacific sockeye salmon, Fish Physiol. Biochem. 38 (2012) 1131-1143. http://10.1007/s10695-011-9599-4.

[3] A.Y. Frommel, V. Stiebens, C. Clemmesen, J. Havenhand, Effect of ocean acidification on marine fish sperm (Baltic cod: Gadus morhua), Biogeosciences 7 (2010) 3915-3919. http://10.5194/bg-7-3915-2010.

[4] I.A. Ges, B.L. Ivanov, D.K. Schaffer, E.A. Lima, A.A. Werdich, F.J Baudenbacher, Thin-film IrOx pH microelectrode for microfluidic-based microsystems, Biosens. Bioelectron. 21 (2005) 248-256. http://10.1016/j. bios.2004.09.021.

[5] A.A. Venn, E. Tambutte, M. Holcomb, J. Laurent, D. Allemand, S. Tambutte, Impact of seawater acidification on $\mathrm{pH}$ at the tissue-skeleton interface and calcification in reef corals, Proc. Natl. Acad. Sci. U. S. A. 110 (2013) 1634-1639. http://10.1073/pnas.1216153110.

[6] a.m. El Badawy, T.P. Luxton, R.G. Silva, K.G. Scheckel, M.T. Suidan, T.M. Tolaymat, Impact of environmental conditions $(\mathrm{pH}$, ionic strength, and electrolyte type) on the surface charge and aggregation of silver nanoparticles suspensions, Environ. Sci. Technol. 44 (2010) 1260-1266. http://10.1021/ es902240k.

[7] G.E. Hofmann, J.E. Smith, K.S. Johnson, U. Send, L.A. Levin, F. Micheli, A. Paytan, N.N. Price, B. Peterson, Y. Takeshita, P.G. Matson, E.D. Crook, K.J. Kroeker, M.C. Gambi, E.B. Rivest, C.A. Frieder, P.C. Yu, T.R. Martz, High-frequency dynamics of ocean pH: a multi-ecosystem comparison, PLoS One 6 (2011). http://10.1371/ journal.pone.0028983.

[8] J.C. Orr, V.J. Fabry, O. Aumont, L. Bopp, S.C. Doney, R.A. Feely, A. Gnanadesikan, N. Gruber, A. Ishida, F. Joos, R.M. Key, K. Lindsay, E. Maier-Reimer, R. Matear, P. Monfray, A. Mouchet, R.G. Najjar, G.K. Plattner, K.B. Rodgers, C.L. Sabine, J.L. Sarmiento, R. Schlitzer, R.D. Slater, I.J. Totterdell, M.F. Weirig, Y. Yamanaka, A. Yool, Anthropogenic ocean acidification over the twenty-first century and its impact on calcifying organisms, Nature 437 (2005) 681-686. http://10.1038/ nature04095.

[9] C.C. Mayorga Martinez, R.E. Madrid, C.J. Felice, A pH sensor based on a stainless steel electrode electrodeposited with iridium oxide, IEEE Trans. Educ. 52 (2009) 133-136. http://10.1109/te.2008.921451.

[10] S. Yao, M. Wang, M. Madou, A pH electrode based on melt-oxidized iridium oxide, J. Electrochem. Soc. 148 (2001) H29-H36. http://10.1149/1.1353582.

[11] M. Khalil, S. Wang, J. Yu, R.L. Lee, N. Liu, Electrodeposition of iridium oxide nanoparticles for pH sensing electrodes, J. Electrochem. Soc. 163 (2016) B485B490. http://10.1149/2.0391609jes.

[12] J.Y. Kim, Y.H. Lee, Pd-PdO pH microprobe for local $\mathrm{pH}$ measurement, Biotechnol. Bioeng. 34 (1989) 131-136. http://10.1002/bit.260340118.

[13] A.N. Bezbaruah, T.C. Zhang, Fabrication of anodically electrodeposited iridium oxide film $\mathrm{pH}$ microelectrodes for microenvironmental studies, Anal. Chem. 74 (2002) 5726-5733. http://10.1021/ac020326l.

[14] A. Fog, R.P. Buck, Electronic semiconducting oxides as pH sensors, Sens. Actuators 5 (1984) 137-146. http://10.1016/0250-6874(84)80004-9.

[15] W. Lonsdale, M. Wajrak, K. Alameh, $\mathrm{RuO}_{2} \mathrm{pH}$ sensor with super-glue-inspired reference electrode, Sensors 17 (2017). http://10.3390/s17092036.

[16] K. Xu, X. Zhang, C. Chen, M. Geng, Development and performance of an allsolid-stated pH sensor based on modified membranes, Int. J. Electrochem. Sci. 13 (2018) 3080-3090. http://10.20964/2018.03.04.

[17] D. Midgley, A review of $\mathrm{pH}$ measurement at high-temperatures, Talanta 37 (1990) 767-781. http://10.1016/0039-9140(90)80118-y.

[18] Q. Dong, D. Song, Y. Huang, Z. Xu, J.H. Chapman, W.S. Willis, B. Li, Y. Lei, Hightemperature annealing enabled iridium oxide nanofibers for both nonenzymatic glucose and solid-state pH sensing, Electrochim. Acta 281 (2018) 117-126. http://10.1016/j.electacta.2018.04.205.

[19] P. Karfa, K.C. Majhi, R. Madhuri, Shape-dependent electrocatalytic activity of iridium oxide decorated erbium pyrosilicate toward the hydrogen evolution reaction over the entire pH range, ACS Catal. 8 (2018) 8830-8843. http:// 10.1021/acscatal.8b01363.
[20] X.Y. Kang, J.Q. Liu, H.C. Tian, C. Zhang, B. Yang, Y. NuLi, H.Y. Zhu, C.S. Yang, Controlled activation of iridium film for AIROF microelectrodes, Sens. Actuators B 190 (2014) 601-611. http://10.1016/j.snb.2013.08.085.

[21] H. Ooka, A. Yamaguchi, T. Takashima, K. Hashimoto, R. Nakamura, Efficiency of oxygen evolution on iridium oxide determined from the $\mathrm{pH}$ dependence of charge accumulation, J. Phys. Chem. C 121 (2017) 17873-17881. http://10.1021/ acs.jpcc.7b03749.

[22] W.D. Huang, H. Cao, S. Deb, M. Chiao, J.C. Chiao, A flexible pH sensor based on the iridium oxide sensing film, Sens. Actuators A 169 (2011) 1-11. http:// 10.1016/j.sna.2011.05.016.

[23] M.A. Petit, V. Plichon, Anodic electrodeposition of iridium oxide films, J. Electroanal. Chem. 444 (1998) 247-252. http://10.1016/s0022-0728(97) 00570-6.

[24] M.L. Hitchman, S. Ramanathan, Evaluation of iridium oxide electrodes formed by potential cycling as pH probes, Analyst 113 (1988) 35-39. http://10.1039/ an9881300035.

[25] C.C.M. Martinez, R.E. Madrid, C.J. Felice, A pH sensor based on a stainless steel electrode electrodeposited with iridium oxide, IEEE Trans. Educ. 52 (2009) 133-136. http://10.1109/te.2008.921451.

[26] H.A. Elsen, C.F. Monson, M. Majda, Effects of electrodeposition conditions and protocol on the properties of iridium oxide $\mathrm{pH}$ sensor electrodes, J. Electrochem. Soc. 156 (2009) F1-F6. http://10.1149/1.3001924.

[27] J. Rouhi, Development of iridium oxide sensor for surface $\mathrm{pH}$ measurement of a corroding metal under deposit, Int. J. Electrochem. Sci. 12 (2017) 9933-9943. http://10.20964/2017.11.07.

[28] S.a.m. Marzouk, Improved electrodeposited iridium oxide pH sensor fabricated on etched titanium substrates, Anal. Chem. 75 (2003) 12581266. http://10.1021/ac0261404.

[29] E.E.-D.M. El-Giar, D.O. Wipf, Microparticle-based iridium oxide ultramicroelectrodes for $\mathrm{pH}$ sensing and imaging, J. Electroanal. Chem. 609 (2007) 147-154. http://10.1016/j.jelechem.2007.06.022.

[30] K. Yamanaka, Anodically electrodeposited iridium oxide-films (aeirof) from alkaline-solutions for electrochromic display devices, Jpn. J. Appl. Phys. Part 1 28 (1989) 632-637. http://10.1143/jjap.28.632.

[31] T.Y. Kim, S. Yang, Fabrication method and characterization of electrodeposited and heat-treated iridium oxide films for $\mathrm{pH}$ sensing, Sens. Actuators B 196 (2014) 31-38. http://10.1016/j.snb.2014.02.004.

[32] J.E. Baur, T.W. Spaine, Electrochemical deposition of iridium(IV) oxide from alkaline solutions of iridium(III) oxide, J. Electroanal. Chem. 443 (1998) 208216. http://10.1016/s0022-0728(97)00532-9.

[33] A. Salimi, V. Alizadeh, R.G. Compton, Disposable amperometric sensor for neurotransmitters based on screen-printed electrodes modified with a thin iridium oxide film, Anal. Sci. 21 (2005) 1275-1280. http://10.2116/ analsci.21.1275.

[34] T. Yoshino, N. Baba, K. Arai, Electrochromic irox thin-films formed in sulfatoiridate (iii,iv) complex solution by periodic reverse current electrolysis (PRIROF), Jpn. J. Appl. Phys. Part 126 (1987) 1547-1549. http:// 10.1143/jjap.26.1547.

[35] Z. Zhu, X.Y. Liu, Z.N. Ye, J.Q. Zhang, F.H. Cao, J.X. Zhang, A fabrication of iridium oxide film pH micro-sensor on Pt-ultramicroelectrode and its application on in-situ pH distribution of 316L stainless steel corrosion at open circuit potential, Sens. Actuators B 255 (2018) 1974-1982. http://10.1016/j. snb.2017.08.219.

[36] M. Zea, A. Moya, M. Fritsch, E. Ramon, R. Villa, G. Gabriel, Enhanced performance stability of iridium oxide-based $\mathrm{pH}$ sensors fabricated on rough inkjet-printed platinum, ACS Appl. Mater. Interfaces 11 (2019) 15160-15169. http://10.1021/acsami.9b03085.

[37] R.K. Jaworski, J.A. Cox, B.R. Strohmeier, Characterization of oxide-films electrochemically deposited from solutions of palladium-chloride and sodium hexachloroiridate, J. Electroanal. Chem. 325 (1992) 111-123. http:// 10.1016/0022-0728(92)80105-d.

[38] C.C. Wu, W.C. Lin, S.Y. Fu, The open container-used microfluidic chip using IrOx ultramicroelectrodes for the in situ measurement of extracellular acidification, Biosens. Bioelectron. 26 (2011) 4191-4197. http://10.1016/j.bios.2011.04.034.

[39] P. Steegstra, E. Ahlberg, In situ pH measurements with hydrous iridium oxide in a rotating ring disc configuration, J. Electroanal. Chem. 685 (2012) 1-7. http://10.1016/j.jelechem.2012.07.040.

[40] C.S. Santos, A.S. Lima, D. Battistel, S. Daniele, M. Bertotti, Fabrication and use of dual-function iridium oxide coated gold secm tips. An application to $\mathrm{pH}$ monitoring above a copper electrode surface during nitrate reduction, Electroanalysis 28 (2016) 1441-1447. http://10.1002/elan.201501082.

[41] P. Vanhoudt, Z. Lewandowski, B. Little, Iridium oxide $\mathrm{pH}$ microelectrode, Biotechnol. Bioeng. 40 (1992) 601-608. http://10.1002/bit.260400507.

[42] K. Nishio, T. Tsuchiya, Electrochromic thin films prepared by sol-gel process, Sol. Energy Mater. Sol. Cells 68 (2001) 279-293. http://10.1016/s0927-0248 (00)00362-7.

[43] L.D. Burke, D.P. Whelan, A voltammetric investigation of the charge storage reactions of hydrous iridium oxide layers, J. Electroanal. Chem. 162 (1984) 121-141. http://10.1016/s0022-0728(84)80159-X.

[44] X. Zhang, Y. Ye, Y. Kan, Y. Huang, J. Jia, Y. Zhao, C.-T.A. Chen, H. Qin, A new electroplated $\operatorname{Ir} / \operatorname{Ir}(\mathrm{OH}) \mathrm{x}$ pH electrode and its application in the coastal areas of Newport Harbor, California, Acta Oceanolog. Sin. 36 (2017) 99-104. http:// 10.1007/s13131-017-1064-5.

[45] M.L. Hitchman, S. Ramanathan, Considerations of the $\mathrm{pH}$-dependence of hydrous oxide-films formed on iridium by voltammetric cycling, Electroanalysis 4 (1992) 291-297. http://10.1002/elan.1140040306. 
[46] G. Beni, C.E. Rice, J.L. Shay, Electrochrmoism of anodic iridium oxide-films. III. Anion mechanism, J. Electrochem. Soc. 127 (1980) 1342-1348. http://10.1149/ 1.2129896.

[47] K.G. Kreider, M.J. Tarlov, J.P. Cline, Sputtered thin-film pH electrodes of platinum, palladium, ruthenium, and iridium oxides, Sens. Actuators B 28 (1995) 167-172. http://10.1016/0925-4005(95)01655-4.

[48] T. Katsube, I. Lauks, J.N. Zemel, pH-sensitive sputtered iridium oxide-films, Sens. Actuators 2 (1982) 399-410. http://10.1016/0250-6874(81)80060-1.

[49] F.F. Huang, Z.W. Wan, Y. Jin, L. Wen, The effects of cyclic isothermal oxidation on $\mathrm{Ir} / \mathrm{IrOx} \mathrm{pH}$ electrode and a method to correct the potential drift of metal oxide electrode, J. Electrochem. Soc. 164 (2017) B632-B640. http://10.1149/ 2.0641713jes].

[50] M. Wang, S. Yao, M. Madou, A long-term stable iridium oxide pH electrode Sens. Actuators B 81 (2002) 313-315. http://10.1016/s0925-4005(01)00972-8.

[51] S. Fierro, A. Kapalka, C. Comninellis, Electrochemical comparison between $\mathrm{IrO}_{2}$ prepared by thermal treatment of iridium metal and $\mathrm{IrO}_{2}$ prepared by thermal decomposition of $\mathrm{H}_{2} \mathrm{IrCl}_{6}$ solution, Electrochem. Commun. 12 (2010) 172-174 http://10.1016/j.elecom.2009.11.018.

[52] C.M. Nguyen, W.D. Huang, S. Rao, H. Cao, U. Tata, M. Chiao, J.C. Chiao, Sol-ge iridium oxide-based $\mathrm{pH}$ sensor array on flexible polyimide substrate, IEEE Sens. J. 13 (2013) 3857-3864. http://10.1109/jsen.2012.2236551.

[53] J.V. Dobson, P.R. Snodin, H.R. Thirsk, Emf-measurements of cells employing metal-metal oxide electrodes in aqueous chloride and sulfate electrolytes at temperatures between 25-250 degreesc, Electrochim. Acta 21 (1976) 527-533. http://10.1016/0013-4686(76)85143-2.

[54] M. Wang, S. Yao, Carbonate-melt oxidized iridium wire for $\mathrm{pH}$ sensing, Electroanalysis 15 (2003) 1606-1615. http://10.1002/elan.200302723.

[55] C. Ratanaporncharoen, M. Tabata, N. Watanagool, T. Goda, A. Matsumoto, M Sriyudthsak, Y. Miyahara, Characterization and optimization of thermally grown iridium oxide and its application to $\mathrm{pH}$ sensors, Sens. Mater. 30 (2018) 1175-1185. http://10.18494/sam.2018.1733.

[56] J.P. Ndobo-Epoy, E. Lesniewska, J.P. Guicquero, Nano-pH sensor for the study of reactive materials, Anal. Chem. 79 (2007) 7560-7564. http://10.1021/ ac070706c.

[57] T. Xiao, F. Wu, J. Hao, M. Zhang, P. Yu, L. Mao, In vivo analysis with electrochemical sensors and biosensors, Anal. Chem. 89 (2017) 300-313. http://10.1021/acs.analchem.6b04308.

[58] X. Chai, X. Zhou, A. Zhu, L. Zhang, Y. Qin, G. Shi, Y. Tian, A two-channel ratiometric electrochemical biosensor for in vivo monitoring of copper ions in a rat brain using gold truncated octahedral microcages, Angew. Chem. Int. Ed. Engl. 52 (2013) 8129-8133. http://10.1002/anie.201302958.

[59] S.C. Cork, A. Eftekhar, K.B. Mirza, C. Zuliani, K. Nikolic, J.V. Gardiner, S.R. Bloom, C. Toumazou, Extracellular $\mathrm{pH}$ monitoring for use in closed-loop vagus nerve stimulation, J. Neural Eng. 15 (2018). http://10.1088/1741-2552/aa8239.

[60] N.M. Lucey, C. Lombardi, M. Florio, S.D. Rundle, P. Calosi, M.C. Gambi, A comparison of life-history traits in calcifying Spirorbinae polychaetes living along natural pH gradients, Mar. Ecol. Prog. Ser. 589 (2018) 141-152. http:/ 10.3354/meps12453.

[61] L. Kapsenberg, A. Miglioli, M.C. Bitter, E. Tambutte, R. Dumollard, J.P. Gattuso, Ocean $\mathrm{pH}$ fluctuations affect mussel larvae at key developmental transitions, Proc. R. Soc. B 285 (2018). http://10.1098/rspb.2018.2381.

[62] A.W. Griffith, C.J. Gobler, Transgenerational exposure of north atlantic bivalves to ocean acidification renders offspring more vulnerable to low $\mathrm{pH}$ and additional stressors, Sci. Rep. 7 (2017). http://10.1038/s41598-017-11442-3.

[63] A.C. Lane, J. Mukherjee, V.B.S. Chan, V. Thiyagarajan, Decreased pH does not alter metamorphosis but compromises juvenile calcification of the tube worm Hydroides elegans, Mar. Biol. 160 (2013) 1983-1993. http://10.1007/s00227 012-2056-9.

[64] D.O. Wipf, F.Y. Ge, T.W. Spaine, J.E. Bauer, Microscopic measurement of pH with iridium oxide microelectrodes, Anal. Chem. 72 (2000) 4921-4927. http:// 10.1021/ac000383j.

[65] F. Zhao, L.M. Zhang, A.W. Zhu, G.Y. Shi, Y. Tian, In vivo monitoring of local pH values in a live rat brain based on the design of a specific electroactive molecule for $\mathrm{H}^{+}$, Chem. Commun. 52 (2016) 3717-3720. http://10.1039/ c5cc09540a.
[66] D. O'Hare, K.H. Parker, C.P. Winlove, Metal-metal oxide pH sensors for physiological application, Med. Eng. Phys. 28 (2006) 982-988. http://10.1016/j. medengphy.2006.05.003.

[67] S. Bause, M. Decker, F. Gerlach, J. Nather, F. Koster, P. Neubauer, W. Vonau, Development of an iridium-based $\mathrm{pH}$ sensor for bioanalytical applications, J. Solid State Electrochem. 22 (2018) 51-60. http://10.1007/s10008-017-3721-1.

[68] M. Tabata, H. Yang, F. Mannan, Y. Katayama, T. Goda, A. Matsumoto, A. Seichi, K. Suzuki, Y. Miyahara, IEEE, Electrochemical Real-Time Monitoring of Isothermal Nucleic Acid Amplification for Quantitative Analysis, (2015) .

[69] I.A. Ges, B.L. Ivanov, A.A. Werdich, F.J. Baudenbacher, Differential pH measurements of metabolic cellular activity in nl culture volumes using microfabricated iridium oxide electrodes, Biosens. Bioelectron. 22 (2007) 1303-1310. http://10.1016/j.bios.2006.05.033.

[70] B.P. Nadappuram, K. McKelvey, R. Al Botros, A.W. Colburn, P.R. Unwin, Fabrication and characterization of dual function nanoscale $\mathrm{pH}$-scanning ion conductance microscopy (SICM) probes for high resolution $\mathrm{pH}$ mapping, Anal. Chem. 85 (2013) 8070-8074. http://10.1021/ac401883n.

[71] A. Salimi, V. Alizadeh, R. Hallaj, Amperometric detection of ultra trace amounts of $\mathrm{Hg}(\mathrm{I})$ at the surface boron doped diamond electrode modified with iridium oxide, Talanta 68 (2006) 1610-1616. http://10.1016/j.talanta.2005.08.048.

[72] A. Salimi, M.E. Hyde, C.E. Banks, R.G. Compton, Boron doped diamond electrode modified with iridium oxide for amperometic detection of ultra trace amounts of arsenic(III), Analyst 129 (2004) 9-14. http://10.1039/ b312285a.

[73] X. Zhang, Y. Ye, Y.T. Kan, Y.F. Huang, J.J. Jia, Y. Zhao, C.T.A. Chen, H.W. Oin, A new electroplated $\mathrm{Ir} / \mathrm{Ir}(\mathrm{OH}) \mathrm{x} \mathrm{pH}$ electrode and its application in the coastal areas of Newport Harbor, California, Acta Oceanolog. Sin. 36 (2017) 99-104. http:// 10.1007/s13131-017-1064-5.

[74] Y.F. Zhou, L.A. Mur, A. Edwards, J. Davies, J.W. Han, H.W. Qin, Y. Ye, A novel chemical sensor with multiple all-solid-state electrodes and its application in freshwater environmental monitoring, Water Sci. Technol. 78 (2018) 432-440. http://10.2166/wst.2018.310.

[75] G.A. Defe, A.Z.C. Antonio, IEEE, Multi-parameter water quality monitoring device for grouper aquaculture, 2018 IEEE 10th International Conference on Humanoid, Nanotechnology, Information Technology, Communication and Control, Environ. Manag. (2018).

[76] R.R. Wu, C.H. Tao, X.G. Chen, Y. Ye, X.H. Yue, Y.Q. Huang, Y.F. Zhou, Q.Q. Wang, Fabrication of multi-parameter chemical sensor and its application in the Longqi hydrothermal field, Southwest Indian Ocean, Int. J. Electrochem. Sci. 14 (2019) 3871-3884. http://10.20964/2019.03.66.

[77] W. Ding, Y.C. Ma, in: D.L. Li, Y.Y. Chen (Eds.), The Application of Wireless Sensor in Aquaculture Water Quality Monitoring, Computer and Computing Technologies in Agriculture V, Pt III, 2012, pp. 502.

[78] A. Sun, T. Phelps, C.Y. Yao, A.G. Venkatesh, D. Conrad, D.A. Hall, Smartphonebased $\mathrm{pH}$ sensor for home monitoring of pulmonary exacerbations in cystic fibrosis, Sensors 17 (2017). http://10.3390/s17061245.

[79] W.J. Cai, C.E. Reimers, The development of $\mathrm{pH}$ and $\mathrm{pCO}_{2}$ microelectrodes for studying the carbonate chemistry of pore waters near the sediment-water interface, Limnol. Oceanogr. 38 (1993) 1762-1773. http://10.4319/ lo.1993.38.8.1762.

[80] D. Archer, S. Emerson, C. Reimer, Dissolution of calcite in deep-sea sediments $\mathrm{pH}$ and $\mathrm{O}_{2}$ microelectrode results, Geochim, Cosmochim. Acta 53 (1989). http://10.1016/0016-7037(89)90161-0.

[81] E.T. Peltzer, X. Zhang, p.m. Walz, M. Luna, P.G. Brewer, In situ raman measurement of $\mathrm{HS}^{-}$and $\mathrm{H}_{2} \mathrm{~S}$ in sediment pore waters and use of the $\mathrm{HS}^{-}: \mathrm{H}_{2} \mathrm{~S}$ ratio as an indicator of pore water pH, Mar. Chem. 184 (2016) 32-42. http:// 10.1016/j.marchem.2016.05.006.

[82] Z.X. Tian, X. Zhang, C.L. Liu, Q.G. Meng, J. Yan, Feasibility study on quantitative analysis of sulfide concentration and $\mathrm{pH}$ of marine sediment pore water via raman spectroscopy, Spectrosc. Spect. Anal. 35 (2015) 649-656. http:// 10.3964/j.issn.1000-0593(2015)03-0649-08.

[83] K.M. Xu, L.P. Zhang, Development of metal oxide microelectrodes for measuring sediment pH, J. Xiamen University (Natural Science) 48 (2009) $570-575$. 